\title{
Ultrastructure of Capillaries in the Odontoblastic Layer
}

\author{
R. E. CORPRON, J. K. AVERY, and S. D. LEE
}

Departments of Pedodontics and Oral Biology, School of Dentistry, The University of Michigan, Ann Arbor, Michigan 48104, USA

Terminal extensions of subodontoblastic capillaries have been observed histologically among odontoblasts in coronal pulp in a variety of species, including man. James ( $J$ Anat 89:54749, 1955), Adams (J Dent Res 38:968-78, 1959), Klingsberg et al (J Dent Res 38:419, 1959), Adams (Arch Oral Biol 7:773-774, 1962), and Jesson (Acta Odontol Scand 25: $491-523,1967)$ observed capillaries at varying depths among odontoblasts, but not in contact with the predentinal surface.

This study was carried out to clarify the ultrastructural relationships of terminal capillaries in the odontoblastic layer of coronal pulp. Present observations are from 70 first molars in functional occlusion in 35 white mice (30 to 60 days old). The teeth were extracted and fixed $1.33 \%$ osmic acid in $s$-collidine buffer at $4 \mathrm{C}$ for two hours, dehydrated through graded ethanol and propylene oxide, embedded in Epon 812, sectioned at 500 to $800 \mathrm{~A}$, stained with uranyl acetate, and viewed with an electron microscope.*

The capillaries were located at varying depths within the odontoblastic layer and frequently were close to the predentinal surface in the pulpal horns (Fig 1). In older teeth (50 to 60 days), the capillaries seemed closer to the predentin than in the younger molars (30 to 40 days).

The ultrastructure of the terminal capillaries revealed an endothelial-lined channel with a lumen slightly larger than one red blood cell (Fig 1). The wall of the endothelial cell was thin with an irregular-shaped nucleus. Intracytoplasmic structures included several elements of rough endoplasmic reticulum, occasional small, round mitochondria, and frequent pinocytotic microvesicles. Along the more flattened side of the capillary opposite the nucleus, occasional pores or fenestrations appeared in the endothelial cell wall (Fig 2). A continuous basement lamina enclosed the periphery of the capillary and separated the endothelial cell wall from the thin extensions of the pericytes or adjacent odontoblasts. The terminal capillaries were not encircled completely by the processes of the pericytes and were classified as A-1-alpha capillaries (BENNETT ET AL, Am J Physiol 196: 381-90, 1959).

Fenestrations of the terminal capillaries among odontoblasts appeared in the region of the endothelial cell wall not enclosed by pericytes (Fig 2); this left only the basal lamina separating the capillary pores from adjacent odontoblasts. This arrangement allows

This work was supported by USPHS Research Grant DE-01604 from the National Institute of Dental Research, National Institutes of Health, Bethesda, Md.

Received for publication August 14, 1972.

* Hitachi 8, Hitachi Ltd., Tokyo, Jap. rapid transfer (FARQUHAR, Angiology 12:270$90,1961)$ from such capillaries to the adjacent odontoblast, and represents a unique structural-functional relationship in terminal capillaries, since fenestrations are absent in more pulpally located capillaries (KUKLETOVA, Scripta Medica 43:109-16, 1970; HAN and AVERY, Anat Rec 145:542-72, 1963; Matthews ET AL, J Dent Res 38:940-46, 1959).

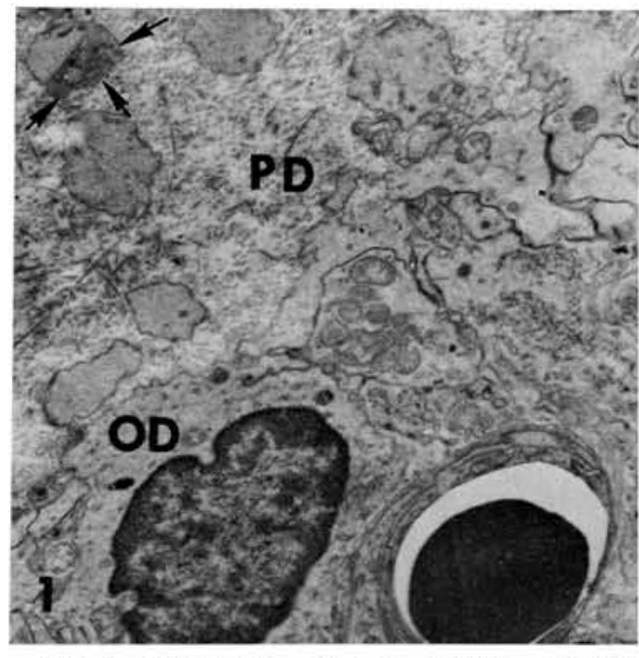

FIG 1.-Capillary (lower right) located among odontoblasts $(O D)$ near predentin $(P D)$. Small nerve (arrows) is located in predentin (orig mag $\times 8000$, reproduced at $83 \%$ ).

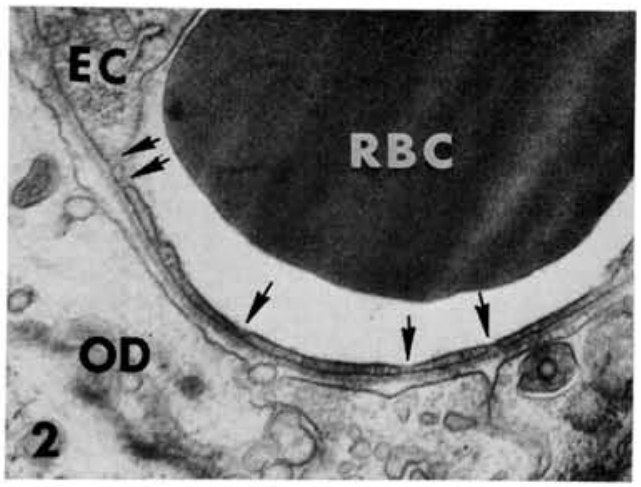

FIG 2.-Fenestrations (arrows) in thin section of endothelial cell $(E C)$. Continuous basal lamina separates capillary wall from adjacent odontoblast $(O D) . R B C$, red blood cell (orig mag $\times 32,000$, reproduced at $83 \%$ ). 